УДК 338.3

ББК 65.5

КОМПЛЕКСНАЯ БЕЗОПАСНОСТЬ: ПОДХОДЫ К МЕТОДОЛОГИИ ИНДИКАТИВНОГО АНАЛИЗА

\author{
А.Л. ПАСТУХОВ \\ alpast@yandex.ru \\ кан. философских наук, доцент \\ доцент кафедры безопасности
}

Российская академия народного хозяйства и государственной службы

при Президенте Российской Федерации Северо-Западный институт управления

г. Санкт-Петербург, Российская Федерация

Ю.В. МЕЛЕШКО

meleshkojv@gmail.com

кан. экон. наук, доцент кафедры «Экономика и право»

Белорусский национальный технический университет

г. Минск, Республика Беларусь

Статья посвящена управлению в системе начиональной и региональной безопасности в современных социально-экономических условиях в контексте глобализащии. Представлены условия формирования комплексного подхода к системе безопасностью, включая выбор показателей и критериев, произведен анализ существующих моделей оценки национальной безопасности и предложен концептуальный подход к моделированию системы комплексной безопасности.

Ключевые слова: безопасность, национальная безопасность, комплексная безопасность, показатели безопасности, критерии оценки опасности.

\title{
THE COMPREHENSIVE SECURITY: APPROACHES TO THE METHODOLOGY OF INDICATIVE ANALYSIS
}

\section{A.L.PASTUKHOV}

PhD, Associate Professor, Docent of the department «Security»

The Russian Presidential Academy of National Economy and Public Administration

North-West Institute of Management

St. Petersburg, Russian Federation

Yu.V. MELESHKO

$\mathrm{PhD}$ in Economics, Associate Professor of the Department of Economics and Law

Belarusian National Technical University

Minsk, Republic of Belarus

The article is devoted to the management in the system of national and regional security in the current socio-economic conditions in the context of the globalization.

It presents the conditions for the formation of an integrated approach to the security system, including the choice of indicators and criteria, the analysis models of the national security assessment, and suggests a conceptual approach to the modeling an integrated security system.

Keywords: security, national security, integrated security, safety indicators, hazard assessment criteria. 


\section{ВВЕДЕНИЕ}

В период роста общемировой и внутригосударственной нестабильности, изменения международных институтов и правил их функционирования, создания гибких систем международных отношений, когда страны, как например, Турция, могут, с одной стороны, находится в объединении, действия которого носят характер, позволяющий их идентифицировать как угрозы национальной безопасности Российской Федерации, а с другой стороны, одновременно развивать сотрудничество на сепаратной основе и даже стремиться к вступлению в дружественные политические или экономические объединения (ЕАЭС, ШОС), создание гибкой комплексной системы национальной безопасности является важной институциональной основой, способной обеспечить относительную стабильность существования и предсказуемость экономического и социально-политического развития государства.

Вопросы комплексной безопасности представлены в трудах таких отечественных ученых, как А. В. Климов, Я. В. Сычев, Т. Г. Габричидзе, Т. В. Владимирова, В. А. Шестаков, В. Л. Шульц и др. Однако, большинство научных трудов по комплексной безопасности имеют узкоспециализированную отраслевую или моносферную направленность и не рассматривают достаточно детально теоретико-методологические и методические основы.

В данном контексте, методологически, важно определить набор критериев и показателей, позволяющий осуществлять государственное управление в различных сфеpax, обеспечивающих минимизацию имеющихся рисков и позволяющих гибко и адекватно реагировать на изменения внешней и внутренней среды.

\section{РЕЗУЛЬТАТЫ И ИХ ОБСУЖДЕНИЕ}

В работах отечественных и зарубежных ученых по вопросам безопасности мы можем выделить несколько концептуальных подходов к решению данного вопроса.

Так, например, в середине прошлого столетия профессор Принстонского университета Клаусс Кнорр, рассматривая проблемы национальной безопасности сформулировал понятие «национальная мощь», которая, по его мнению, включает в себя следующие компоненты:

- экономические возможности;

- способность страны к военной мобилизации;

- административную соревновательность.

Позднее, другой профессор из Кембриджского университета Г. Клиффорд предложил формулу расчета национальной мощи:

$$
\mathrm{P}=\mathrm{N}(\mathrm{L}+\mathrm{C}+\mathrm{I}+\mathrm{M})
$$

где: $\quad$ Р - мощь государства;

$\mathrm{N}$ - ядерные возможности;

$\mathrm{L}$ - территория;

С- население;

I - индустриальный базис;

М - размеры военных ресурсов [1].

Г. Клиффорд выделил обладание военными ресурсами как основной показатель, обеспечивающий независимость, суверенитет государства в системе международных отношений. 
В 1963 г. профессором Д. Стингером для оценки национальных возможностей был предложен комплексный показатель, включающий военные расходы, численность Вооруженных Сил (в краткосрочной перспективе), производством чугуна и стали, а также потреблением электрической энергии (в среднесрочной перспективе), численность населения и уровень урбанизации (в долгосрочной перспективе). Аналогичные показатели предложил применять профессор Берлинского технического университета Вильгельм Фуке в 1965 г. [1].

Действительно, за последние 70-лет не было случаев военной агрессии какойлибо из стран в отношении государства, обладающего ядерным оружием, не считая приграничного конфликта между Индией и Пакистаном в конце XX - начале XXI века с участием международных террористических группировок. Зато стали фактом нападение международной коалиции в составе стран, обладающих ядерным оружием на Югославию, а затем Ливию, с последующей ликвидацией суверенитета.

Однако другие показатели, предложенные К. Кнорром и Г. Клиффордом, требуют определенных уточнений. Так, например, в настоящее время, далеко не всегда размер территории является потенциалом, обеспечивающим национальную безопасность, с учетом изменения характера военных действий и возможностей современной техники уничтожения военной силы и техники, а также военной и гражданской инфраструктуры на всей протяженности территории стран, независимо от ее величины. Более того, большое количество неосвоенной территории государства, не имеющей определенной численности населения и соответствующей инфраструктуры обеспечения является, на наш взгляд, фактором политической нестабильности, стимулирующим агрессивные действия других стран с целью захвата территории. Так, например, конкретизируя идею, изложенную Гербертом Уэллсом в работе «Открытый заговор: чертежи мировой революции», государственный секретарь США Мадлен Олбрайт публично озвучивала утверждение о необходимости установления международного контроля над неосвоенной частью территории Российской Федерации (Сибирь, Дальний Восток).

Численность населения также можно рассматривать в нескольких аспектах: как потенциал экономического роста, обеспечивающий определенную емкость внутреннего рынка товаров и рынка труда, или как потенциал роста вооруженных сил страны, в том числе с учетом мобилизации. Но при этом следует учитывать суммарную профессиональную компетентность населения страны, в том числе обучаемость и интеллектуальные возможности. Практика показывает, что при внедрении современной военной техники и промышленного оборудования в странах, население которых не обладает необходимым интеллектуальным потенциалом и профессиональными знаниями, данная техника и оборудование далеко не всегда получали эффективное применение, поэтому важно учитывать не только общую численность, но и человеческий потенциал и капитал населения для более адекватного определения условий обеспечения экономической, военной и социально-политической стабильности государства.

Понятие индустриального базиса также требует определенного пояснения, так как в настоящее время численность производственных предприятий, имеющегося промышленного оборудования и транспортных средств, объем добычи нефти, угля или электрической энергии являются недостаточными показателями оценки национального потенциала и безопасности страны. Исторический опыт показывает, что немалую роль в данном вопросе играет аграрный потенциал, развитость сельскохозяйственного производства, позволяющего обеспечить население продуктами питания независимо от изменения международных отношений или внутренних конфликтов. Поэтому, на наш взгляд, продовольственная безопасность государства является важным элементом в системе оценки комплексной безопасности. 
Особое значение в обеспечении национальной безопасности имеет ракетно-космическая промышленность. Высокие технологии двойного назначения, широко использующиеся в ракетно-космической промышленности, вносят важный вклад в обеспечение стратегической стабильности и безопасности на всех уровнях. Взаимосвязь военной и гражданской составляющей ракетно-космической промышленности со временем усиливается. Модернизация национальных военно-промышленных комплексов в направлении использования ракетно-космических технологий приводит к повышению национальной военно-экономической мощи, создавая новую картину региональной и мировой безопасности. Сохранение военной составляющей в национальной космической деятельности в совокупности со стремлением сохранить в секрете уникальные технологии, дающие существенное конкурентное преимущества, приводит к ограниченности международного сотрудничества в сфере космических исследований в основном области гражданских космических программ и в значительной степени автономному развитию космической деятельности отдельных государств. Услугами, создаваемыми в области космической деятельности, имеющими стратегическое значение для национальной безопасности, являются, например, национальные системы спутниковой связи, глобальные навигационные спутниковые системы [2].

Размеры военных ресурсов в контексте международных отношений следует рассматривать с учетом как имеющихся у государства, так и ресурсов других стран, которые могут быть использованы для обеспечения стабильности государства и поддержки власти. В 1975 г. Р. Клайн предложил систему оценки государственного потенциала, включающего как объективные, так и субъективные показатели:

$$
\mathrm{P}=(\mathrm{C}+\mathrm{E}+\mathrm{M})(\mathrm{S}+\mathrm{W})
$$

где: $\mathrm{P}$ - мощь государства;

$\mathrm{C}$ - население и территория;

Е - экономические возможности;

М - военная мощь;

$\mathrm{S}$ - коэффициент национальной стратегии;

$\mathrm{W}$ - воля по достижению целей национальной стратегии.

В некоторых методиках оценки национального потенциала, обеспечивающего национальную безопасность, используется такой показатель, как ВВП или его рост. Так, например, в КНР важнейшим индикатором достижения национальной безопасности и международного лидерства рассматривается именно этот экономический показатель. Правительство КНР запланировало на первом этапе провести индустриализацию страны, на втором - обеспечить развитие науки и техники, на третьем - провести цифровизацию и информатизацию общества. Прогноз роста ВВП КНР представлен в таблицах 1 и 2.

Таблица 1 - Прогноз роста ВВП Китая в 2000-2050 годах

\begin{tabular}{|c|c|c|}
\hline $\begin{array}{c}\text { Период, } \\
\text { годы }\end{array}$ & Среднегодовые темпы роста ВВП, \% & $\begin{array}{c}\text { Размер ВВП на конец периода, } \\
\text { трлн. юаней }\end{array}$ \\
\hline $2000-2010$ & 8.1 & 19.8 \\
\hline $2011-2020$ & 6,4 & 36.7 \\
\hline $2021-2030$ & 5,4 & 62.3 \\
\hline $2031-2040$ & 4,9 & 100,5 \\
\hline $2041-2050$ & 4,3 & 153,1 \\
\hline
\end{tabular}

Источник: [3]. 
Таблица 2 - Прогноз изменений структуры ВВП Китая в основных сферах производства и жизни общества

\begin{tabular}{|l|l|l|l|}
\hline \multicolumn{1}{|c|}{$\begin{array}{c}\text { Период, } \\
\text { годы }\end{array}$} & $\begin{array}{c}\text { Сельское хозяйство, } \\
\%\end{array}$ & $\begin{array}{c}\text { Промышленность, } \\
\text { строительство, } \\
\%\end{array}$ & $\begin{array}{c}\text { Транспорт, связь, тор- } \\
\text { говля, услуги, } \\
\%\end{array}$ \\
\hline $2000-2010$ & 14.1 & 51.5 & 34,4 \\
\hline $2011-2020$ & 11,5 & 50,2 & 38.3 \\
\hline $2021-2030$ & 9.4 & 48.0 & 42.6 \\
\hline $2031-2040$ & 7,7 & 45,3 & 46,9 \\
\hline $2041-2050$ & 6,2 & 42,1 & 51,7 \\
\hline
\end{tabular}

Источник: [3].

Однако, анализируя экономические данные стран-участников Второй мировой войны можно увидеть следующее (таблица 1).

Таблица 3 - Валовый внутренний продукт стран-участников Второй мировой войны, млрд. долл. в ценах 1990 г.

\begin{tabular}{|l|c|c|c|c|}
\hline \multicolumn{2}{|c|}{ Страны } & 1938 & 1940 & 1944 \\
\hline 1 & СССР & 359 & 417 & 362 \\
\hline 2 & Германия & 351 & 387 & 437 \\
\hline 3 & Великобритания & 284 & 316 & 346 \\
\hline 4 & США & 800 & 943 & 1499 \\
\hline 5 & Япония & 169 & 192 & 189 \\
\hline 6 & Франция & 186 & 164 & 93 \\
\hline 7 & Австрия & 24 & 27 & 29 \\
\hline 8 & Италия & 141 & 147 & 117 \\
\hline
\end{tabular}

Источник: [6].

Если учитывать, что в первый период военных действий между СССР и Германией в 1941-1945 гг. промышленный потенциал Германии включал в себя промышленные ресурсы Франции, Австрии, Италии, и, кроме того, по количеству станков, Германия занимала первое место в мире, а СССР по программе Ленд-Лиза получил продукции менее 30 млрд. долл., то экономически потенциал Германии являлся большим, чем СССР, однако, этого оказалось недостаточно для ожидаемого результата военных действий.

Возвращаясь к понятию территории в контексте проблем национальной безопасности хотелось бы выделить несколько аспектов, требующих более детального исследования, связанных с применением таких терминов как «стратегические границы», «жизненное пространство», «национальные интересы». Следует отметить, что не всегда экономический и социальный потенциал страны связан с территорией в рамках государственных границ. Рассматривая СССР в период его послевоенного развития следует учитывать не только ВВП, население страны и другие социально-экономические показатели государства, но и ресурсные возможности стран СЭВ (Восточная Европа), отдельных стран Африки и Латинской Америки, экономика и потребление, а также система Вооруженных Сил которых были во многом встроены в Советскую систему.

То же самое сейчас происходит со многими странами, которые находятся в экономической, политической или военной зависимости от ведущих стран мира, имея фактически «условный» суверенитет. В условиях глобализации, создания международных 
экономических систем и большого количества совместных предприятий, а также массового использования высокоточного оборудования, приспособлений и техники иностранного производства.

По материалам КНР к показателям, обеспечивающим национальную безопасность и развитие государства можно отнести такие показатели, как:

- технологии;

- трудовые ресурсы;

- капитал;

- информация;

- природные ресурсы;

-военная мощь;

- ВВП;

-дипломатия;

- контрольно-регулятивная мощь правительства.

В работе В.А. Шестакова и В.А. Антошина предложены такие показатели обеспечение безопасности, как:

1. В экономической сфере: объем инвестиций, уровень инфляции.

2. В социальной сфере: дифференциация доходов населения, коэффициент рождаемости, старения и ожидаемая продолжительность жизни.

3. В сфере экологии: величина налоговых поступлений от экологических платежей и затрат на мероприятия и оборудование, улучшающих экологию.

4. Девиантное поведение: уровень преступности, уровень потребления алкоголя, количество суицидов на душу населения.

5. Политика: уровень доверия граждан к органам власти и доля граждан, выступающих за смену политических лидеров или системы [5, с. 75].

Однако, в условиях современной социокультурной динамики и развития социальноэкономических и политических отношений с учетом процессов глобализации [4, с. 19], по нашему мнению, для создания системы комплексной безопасности необходимо исходить из общего представления об опасностях, их классификациях и классификационных признаках.

По характеру источников, в данном аспекте, мы можем выделить:

- опасности от естественных (природных) процессов и явлений;

- опасности техногенной среды;

- опасности от человека и общественных групп (внутренние), разделенные на три группы: социальные, экономические, политические;

- опасности от человека и международных сообществ, а также государств и корпораций (внешние), также разделенные на три группы: социальные, экономические, политические.

Опасности от естественных (природных) процессов и явлений предполагают количественные и качественные измерения, включая определение количества выявленных опасностей и анализ динамики процессов, а также фиксацию последствий негативного природного воздействия. Соответственно, показателями безопасности могут быть: количество предотвращенных или минимизированных негативных природных явлений; развитие инфраструктуры и средств связи по предупреждению или защите населения от природных опасностей; учет при создании гражданской инфраструктуры вероятности возникновения негативных стихийных явлений; развитие определенных видов страхования и др. В качестве критериев могут быть приняты соотношение предотвращенных или минимизированных негативных природных явлений к общей численности зафиксированных; динамика изменения величины ущерба от негативных природных явлений и т. д. 
Опасности техногенной среды, также включают в себя определение количества выявленных опасностей и анализ динамики процессов, а также фиксацию последствий негативного техногенного воздействия. Соответственно, показателями безопасности могут быть количество предотвращенных или минимизированных негативных техногенных воздействий, развитие системы экологического менеджмента и системы охраны труда в организациях, паспортизация и цифровизация процессов обеспечения безопасности.

В качестве критериев могут быть приняты соотношение предотвращенных или минимизированных негативных техногенных воздействий к общей численности зафиксированных, динамика изменения величины ущерба от негативных техногенных явлений, развитость системы охраны труда, паспортизации и цифровизации производственных процессов, соотношение величины негативного технологического воздействия на окружающую среду и соответствующие нормы и т. д.

Диагностика опасностей и системы безопасности от человека и общественных групп (внутренние) может включать в себя такие показатели как:

- количество лиц и групп, характеризующихся девиантным поведением, совершением действий, относящихся к уголовным преступлениям;

- количество лиц, участвующих в голосованиях на федеральном, региональном и местном уровнях;

- количество лиц, участвующих в несанкционированных общественных мероприятиях и др.

Критериями в данном контексте будут изменение динамики численности лиц и групп, характеризующихся антиобщественным, девиантным поведением, изменение динамики участвующих в голосованиях на всех уровнях, изменение величины среднего дохода граждан и домохозяйств и др.

Рассматривая опасности от нерезидентов (неграждан) и международных сообществ, а также государств и корпораций (внешние) следует выделит такие критерии как:

- количество лиц и групп, характеризующихся антигосударственных, антиобщественным поведением и действиями, включая информационное воздействие;

- инфраструктурная обеспеченность экономики страны;

- численность Вооруженных сил страны и стран «вероятного противника»;

- количество дипломатических конфликтов и др.

Критерии обеспечения национальной безопасности должны включать в себя следующие сферы:

1. Экономическая безопасность (динамика изменения ВНП в сопоставимых ценах, динамика реальных доходов населения, динамика миграции с учетом возрастных и образовательных параметров, изменение национальных запасов валютных ценностей и продуктов питания, динамика разведанных природных ресурсов экономически целесообразных с точки зрения добычи и реализации и др.).

2. Технико-технологическая безопасность (динамика внедрения передовых технологий, изменение количества предприятий, применяющих современные технологии, динамика зарегистрированных патентов с учетом их внедрения и отражения в системе бухгалтерского учета организаций, возможности милитаризации экономики страны и др.).

3. Военная безопасность, включая изменение численности Вооруженных Сил с учетом изменения количества современных вооружений разных видов.

4. Социальная безопасность, включая изменение рождаемости и численности населения, количества лиц трудоспособного возраста, динамики здоровья населения и др. 


\section{ВЫВОДЫ}

Таким образом, в результате проведенного исследования существующих методологических подходов к комплексной безопасности можно сделать вывод о необходимости более полного применения комплексного подхода к разработке моделей и систем безопасности и разработке системы индикативного планирования с учетом не только отдельных количественных, но и качественных условий и показателей, позволяющих более объективно оценить динамику изменения политических, военных, технико-технологических, социальных и иных рисков, и, соответственно, разработать и реализовать комплекс мероприятий, позволяющих улучшить безопасность на всех уровнях в современных социально-экономических условиях с учетом процессов глобализации и усиления влияния международных транснациональных корпораций на национальные экономические процессы и отдельные экономические и социальные явления, включая динамику рынка труда и величины средней заработной платы, изменение цен на товары на внутреннем и внешнем рынках, изменение котировки национальной валюты.

\section{СПИСОК ИСПОЛЬЗОВАННЫХ ИСТОЧНИКОВ}

1.Балахонцев, Н Зарубежные методы оценки потенциала стран / Н.Балахонцев, А.Кондратьев // Зарубежное военное обозрение. 2010.-№11. - С.101-104.

2.Солодовников, С. Ю. Опережающее развитие космической отрасли как основа устойчивого роста белорусской экономики / С. Ю. Солодовников, А. Н. Тур, Ю. В. Мелешко // Вестник Полоцкого государственного университета. Серия D. Экономические и юридические науки/ ПГУ; под. ред. Р. Н. Авласенок. - Новополоцк: ПГУ, 2015. № 14. - С. 8-14.

3.Клименко, А. Ф. Эволюция военной политики и военной доктрины Китая / А. Ф. Клименко // Военная мысль. - 2005. - № 4. - С. 2-17.

4.Пастухов, А. Л. Глобализация в мировоззрении человека / А. Л. Пастухов // Вестник Челябинской государственной академии культуры и искусств. - 2006. - Т. 10. № 2. - С. 19-34.

5.Шестаков, В. А Комплексное управление безопасностью на государственном уровне / В. А. Шестаков, В. А. Антошин // Журнал Вопросы управления. - 2015. - Выпуск 35. - С. 68-77.

6.Harrison, M. The Economics of World War II: Six Great Powers in International Comparison, Cambridge University Press (1998) [Электронный ресурс]. - Режим доступа: https://ru.wikipedia.org/wiki/военное_производство_во_время_второй_мировой_войны. Дата доступа: 12.08.2018.

\section{REFERENCES}

1. Balahoncev, N. Zarubezhnye metody ocenki potenciala stran / N. Balahoncev, A. Kondrat'ev // Zarubezhnoe voennoe obozrenie. - 2010. - № 11. - S. 101-104.

2. Solodovnikov, S. Ju. Operezhajushhee razvitie kosmicheskoj otrasli kak osnova ustojchivogo rosta belorusskoj jekonomiki/ S. Ju. Solodovnikov, A. N. Tur, Ju. V. Meleshko // Vestnik Polockogo gosudarstvennogo universiteta. Serija D. Jekonomicheskie i juridicheskie nauki/ PGU; pod. red. R. N. Avlasenok. - Novopolock: PGU, 2015. - №14. - S.8-14.

3. Klimenko, A. F. Jevoljucija voennoj politiki i voennoj doktriny Kitaja / A. F. Klimenko // Voennaja mysl'. - 2005. - № 4. - S. 2-17. 
4. Pastuhov, A. L. Globalizacija v mirovozzrenii cheloveka / A. L. Pastuhov // Vestnik Cheljabinskoj gosudarstvennoj akademii kul'tury i iskusstv. - 2006. - T. 10. - № 2. - S. 19-34.

5. Shestakov, V. A Kompleksnoe upravlenie bezopasnost'ju na gosudarstvennom urovne / V. A. Shestakov, V. A. Antoshin // Zhurnal Voprosy upravlenija. - 2015. - Vypusk 35. S. $68-77$.

6. Harrison, M The Economics of World War II: Six Great Powers in International Comparison, Cambridge University Press (1998) [Jelektronnyj resurs]. - Rezhim dostupa: https://ru.wikipedia.org/wiki/voennoe_proizvodstvo_vo_vremja_vtoroj_mirovoj_vojny. - Data dostupa: 12.08.2018.

Статья поступила в редакичию 6 сентября 2018 года. 